\title{
Effects Of Ginger Extract On Glomerular Mesangial Matrix Of Kidneys In Alloxan Induced Diabetic Nephropathy Of Albino Rats
}

- - - - - - - - - - - - - - Irshad, Saira Munawar, Areej Rasheed -----------ABSTRACT

Background: For a long time, Diabetes mellitus has been treated with medicines derived from plants.

Objective: To evaluate the effect of Ginger aqueous extract on Glomerular mesangial matrix in Alloxan induced diabetic nephropathy of albino rats.

Materials and Methods: In this study we induced diabetes mellitus with Alloxan intraperitoneally (150 mg/kg body weight) in Experimental groups B \& C. Then the rats of Experimental group C received $200 \mathrm{mg} / \mathrm{kg}$ body weight of ginger aqueous extract by gavage daily for five weeks starting from $8^{\text {th }}$ day after Alloxan injection.

Results: We observed that on histopathological examination, Experimental group B kidneys revealed highly increased mesangial matrix while the animals of experimental group $\mathrm{C}$ treated with ginger aqueous extract showed less increase in mesangial matrix as compared to experimental group B but it was more than control group A. Three groups had significant difference among them having p-values $<0.001$.

Conclusion: The results of the present study indicated that the co-treatment of Ginger aqueous extract prevented alloxan induced diabetic nephropathy in albino rats. The aqueous extract of Ginger showed amazing results regarding renal histopathology of diabetic rats. The overall nephroprotective effect of Ginger is probably due to a counteraction of free radicals by its antioxidant components.

KEY WORDS: Diabetes mellitus, Kidney, Diabetic nephropathy, Ginger, Alloxan

\section{IINTRODUCTION}

Diabetes mellitus (DM) is a syndrome. Its characteristic features include chronic elevated blood glucose levels and relative insulin deficiency, resistance or both ${ }^{1}$. More than 346 million people suffer from DM worldwide ${ }^{2}$. Diabetic complications include heart disease, peripheral vascular disease, nephropathy, retinopathy, neuropathy and renal failure $^{3}$. The kidney is an organ which excretes metabolic waste products ${ }^{4}$. The functions of kidneys are to maintain plasma osmolality, electrolytes concentration and end products excretion ${ }^{5}$. Best index of functioning renal tissue is Glomerular filtration rate (GFR) ${ }^{6}$. One of the leading cause of end stage renal disease is considered to be diabetic nephropathy ${ }^{7}$. One of the structural changes in Diabetic nephropathy is expansion of mesangium. Diffuse expansion of mesangium is called diffuse diabetic glomerulosclerosis ${ }^{8}$. Diabetic nephropathy is due to various mechanisms. One of the pathophysiological mechanisms which is considered

\begin{tabular}{l} 
I Faiza Irshad \\
Assistant Professor. Department of Anatomy. \\
I Islam Medical \& Dental College Sialkot. \\
I Email:faizamufassar@ hotmail.com \\
I Saira Munawar \\
I Assistant Professor. Department of Anatomy. \\
I Gujranwala Medical College. Gujranwala. \\
I Areej Rasheed \\
Assistant Professor. Department of Anatomy. \\
I University of Lahore. \\
I Received: 10-05-2018 \\
| Acced: 22-05-2018 \\
\hline I
\end{tabular}

to be major, is the oxidative stress ${ }^{9}$. Alloxan is a glucose analogue and is routinely used to induce diabetes in experimental animals ${ }^{10}$. In rodents diabetes induced by Alloxan results in nephropathy similar to early stage clinical Diabetic Nephropathy ${ }^{11}$. Alloxan rapidly and selectively accumulates in pancreatic beta cells and induces DNA strand breaks in isolated rat pancreatic islets ${ }^{12}$. Due to its toxicity by selectively destroying insulin-producing pancreatic beta cells, it results in an insulin-dependent diabetes mellitus ${ }^{13}$. Zingiber Officinale Roscoe (Zingiberaceae family) is known as Ginger. Ginger is a source of antioxidants which prevent body against oxidative stress which inturn results in damage to DNA and production of free radicals ${ }^{14}$. Nephroprotective role of ginger is due to polyphenols in $\mathrm{it}^{15}$. Incidence of Diabetes is gradually increasing in our society and the use of anti-diabetic allopathic drugs is indispensible for treating it. Uncontrolled diabetes can result in early failure of kidneys. The study was designed to evaluate the effects of Ginger extract on the histological structure of kidneys in Alloxan induced diabetic nephropathy in albino rats.

\section{MATERIALS AND METHODS}

\section{Animals:}

This study was approved by the Institutional Review Board, Federal postgraduate Medical Institute Lahore, Shaikh Zayed hospital, National Health Research Complex. IRB No: 1208. Ref No: F.39/NHRC/Admin/IRB/389. Dated: 23/11/2012. Total 45 adult wistar albino rats of male sex having weight between 250-300g were randomly selected for the study. They were brought from Veterinary Research Institute, Lahore. These rats were kept in cages in the animal house 
of PGMI, Bird wood road Lahore. Free access to water and food were allowed to the rats. Chick feed No.1 (commercial brand) was given to rats. 12 hour dark/light cycle was observed at room temperature $27^{\circ} \mathrm{C}^{13}$. Prior to study, animals were acclimatized to their surroundings for seven days.

\section{Induction of diabetes:}

After overnight fasting, diabetes was induced in the experimental animals by injecting Alloxan $(150 \mathrm{mg} / \mathrm{kg} \mathrm{BW})^{16}$ intraperitoneally in single dosage, (Sigma-Aldrich, Lot \# BCBD6557V, Cat \# A7413-10G, Pcode: 101054491, USA), prepared one hour before administration in distilled water ${ }^{13}$. After injection, water and food were given. To counter hypoglycemic shock, $10 \%$ glucose solution was given to drink overnight ${ }^{15}$. The plasma glucose concentration (non fasting) was measured by using One Touch Ultra Two Glucometer (Lifescan, Uk) in rats at day 3 after starting the injection ${ }^{17,18}$. The animals which had plasma glucose level above $250 \mathrm{mg} / \mathrm{dl}$ were labelled as diabetics and chosen for the experiment ${ }^{15}$. After diabetes confirmation rats were allowed for 4 days to acclimatize to diabetic conditions.

\section{Ginger aqueous extract preparation:}

Preparation was done in PCSIR, Laboratories Complex, Lahore by the following procedure. Fresh, raw and untreated Ginger was purchased from the market. On crushed ice Ginger roots $(500 \mathrm{~g})$ were peeled then small pieces were made. These were homogenized in $250 \mathrm{ml}$ ice cold water and $750 \mathrm{ml}$ cold, sterile $0.9 \%$ Normal saline solution to form a total volume of $1000 \mathrm{ml}$. Blender was used for homogenization for 12 minutes. Then cheese cloth was used to filter it for three times. It was centrifuged at 2000rpm for ten min. Supernatant fraction was collected and normal saline was used to make its volume $1000 \mathrm{ml}$. As the weight of ginger in start was $500 \mathrm{~g}$ so the concentration of the prepared ginger extract was considered to be $500 \mathrm{mg} / \mathrm{ml}$. Extract was freeze dried in sample tubes at $-20^{\circ} \mathrm{C}$ till the rats were fed ${ }^{13}$. From Department of Chemistry, Forman Christian College Lahore, active ingredients were quantified of by Gas chromatography-mass spectrometry (GC-MS).

\section{Grouping of Animals:}

The animals were divided into three groups i.e normal, nondiabetic (Group A), diabetic untreated (Group B) and diabetic plus ginger treated (group C).

1. Normal (Group A): The rats of this group received distilled water $20 \mathrm{ml} / \mathrm{kg}$ body weight by gavage.

2. Diabetic (Group B): Alloxan $(150 \mathrm{mg} / \mathrm{kg} \mathrm{BW})^{16}$. was injected intraperitoneally for induction of diabetes in rats.

3. Diabetic plus Ginger treated (Group C): After diabetes was confirmed, diabetic rats received $200 \mathrm{mg} / \mathrm{kg}$ body weight of ginger aqueous extract by gavage daily for five weeks starting from eighth day after injection of Alloxan. It was labeled as the $1^{\text {st }}$ day of treatment ${ }^{17}$.

\section{Histological studies:}

After the completion of treatment, all the animals were euthanized by giving morphine $5-24 \mathrm{mg} / \mathrm{kg}$ body weight intraperitoneally as an analgesic agent ${ }^{19}$. and sodium pentabarbitol was intraperitoneally injected in $100 \mathrm{mg} / \mathrm{kg}$ body weight dose ${ }^{20}$. Kidneys were dissected out. Ice cold saline was used to wash the kidneys after isolation. Then they were put in tissue bottles having $10 \%$ formaldehyde for 48 hours. $5 \mu \mathrm{m}$ thick sections were obtained by using rotary microtome and stained with haematoxylin and eosin ${ }^{21}$ and PAS $^{22}$ for histopathological examination.

\section{Statistical analysis:}

Analysis of Data was done by SPSS 22.0. Qualitative data were reported in terms of percentage and frequency of each group. Chi-square test was used for Comparison among groups. $<0.05 \mathrm{P}$-value was significant with $95 \%$ confidence level

\section{RESULTS}

\section{Glomerular Mesangial matrix:}

PAS stained sections of kidneys revealed that glomerular mesangial matrix was normal in control group A (Fig.2) and highly increased in experimental group B (Alloxan Induced Diabetic) with narrowing of space between Bowman's capsule and glomerular capillary loops (Fig.3). Mesangial matrix was less increased in experimental group $\mathrm{C}$ and it was more than control group A (Fig.4). Three groups had significant difference among them having p-values $<0.001$. (Table.1, Fig. 1) Group wise comparison revealed that experimental (B \& C Groups) had difference from control (A Group) having p-values $<0.001$ which was significant. (Table. 2) Experimental (B Group) had difference from experimental ( $\mathrm{C}$ Group) having p-values $<0.001$ which was significant.

\section{DISCUSSION}

Diabetes Mellitus (DM) is not a single disease but a group of metabolic disorders having the common feature of hyperglycaemia ${ }^{1}$. Commonest form of diabetes diagnosed in childhood is diabetes mellitus Type 1. Diabetes mellitus Type 2 have strong association with obesity ${ }^{23}$. Diabetes induced nephropathy is one the known cause of end stage renal disease ${ }^{7}$. Diabetic patients with ESRD are left with the options of haemodialysis, peritoneal dialysis or kidney transplantation ${ }^{24}$. Hyperglycaemia increases the glycosylation of proteins (non-enzymatic) which results in formation of advanced glycosylation end-products (AGE). This increase in serum level of AGE produces changes in morphology of kidney including mesangial cell matrix expansion ${ }^{25}$. Expansion of mesangium results due to accumulation of extracellular matrix (ECM) with increased deposition of type IV and VI collagen, fibronectin and laminin ${ }^{26}$. In our research work Glomerular mesangial matrix was normal in control (A Group) and highly increased in experimental (B 
Effects Of Ginger Extract On Glomerular Mesangial Matrix Of Kidneys In Alloxan Induced Diabetic Nephropathy Of Albino Rats

\begin{tabular}{|c|c|c|c|c|c|c|c|c|}
\hline \multirow{3}{*}{ Groups } & \multicolumn{8}{|c|}{ Glomerular Mesangial matrix } \\
\cline { 2 - 10 } & \multicolumn{2}{|c|}{ Normal } & \multicolumn{2}{c|}{ Less Increased } & \multicolumn{2}{c|}{ Highly Increased } & \multicolumn{2}{|c|}{ Total } \\
\cline { 2 - 10 } & $\mathrm{N}$ & $\%$ & $\mathrm{~N}$ & $\%$ & $\mathrm{~N}$ & $\%$ & $\mathrm{~N}$ & $\%$ \\
\hline A Group & 15 & 100.0 & 0 & 0.0 & 0 & 0.0 & 15 & 100.0 \\
\hline B Group & 0 & 0.0 & 0 & 0.0 & 15 & 100.0 & 15 & 100.0 \\
\hline C Group & 0 & 0.0 & 15 & 100.0 & 0 & 0.0 & 15 & 100.0 \\
\hline Total & 15 & 33.3 & 15 & 33.3 & 15 & 33.3 & 45 & 100.0 \\
\hline
\end{tabular}

Table. 1. Status of glomerular mesangial matrix animals in control (A Group) and Experimental (B \& C Groups)

\begin{tabular}{|l|c|c|c|c|}
\hline (I) Groups & (J) Groups & Chi-Square & Df & P-value \\
\hline \multirow{2}{*}{ A Group } & B Group & 26.13 & 1 & $<0.001 * *$ \\
\cline { 2 - 5 } & C Group & 26.13 & 1 & $<0.001 * *$ \\
\hline B Group & C Group & 26.13 & 1 & $<0.001 * *$ \\
\hline
\end{tabular}

Table. 2. Group wise comparison in control (A Group) and experimental (B \& C Groups) groups for Status of glomerular mesangial matrix

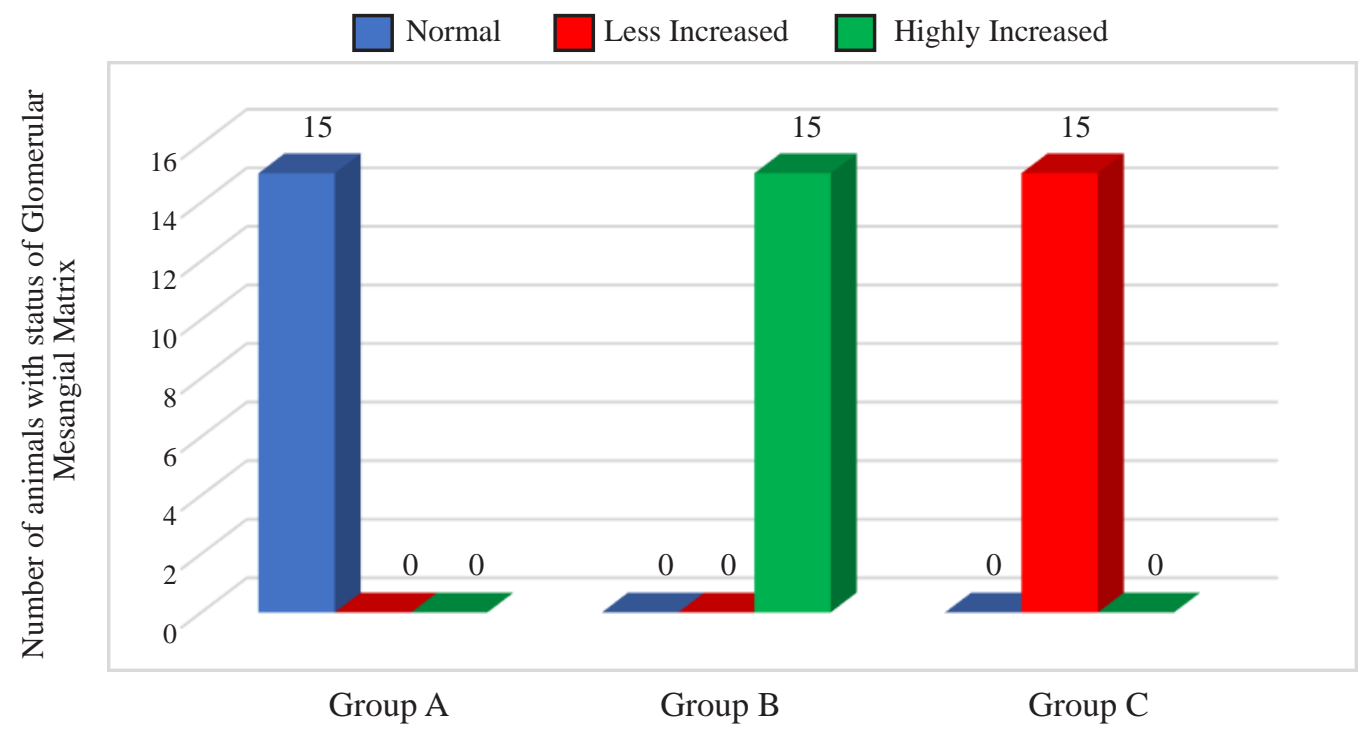

Fig.1 Status of glomerular mesangial matrix in control (A Group) and experimental (B \& C Groups)

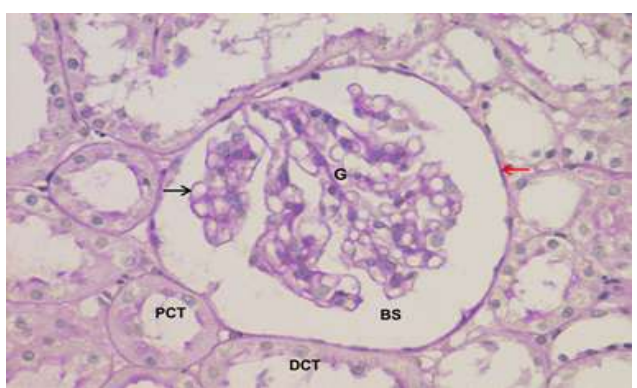

Fig.2 Photomicrograph of Cortex (CX) of kidney rat, Control (A Group) showing Bowman's space (BS), Glomerulus (G), Proximal convoluted tubule (PCT) \& Distal convoluted tubule (DCT). Bowman's capsule (red arrow) and Glomerular basement membrane ( black arrow).(PAS 40x)

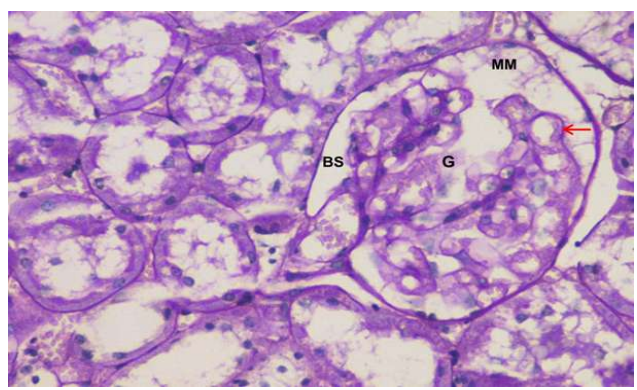

Fig.3 kidney photomicrograph of rat. Experimental (B Group) showing Cortex $(\mathrm{CX})$. Glomerulus $(\mathrm{G})$ with increased mesangial matrix (MM), decreased Bowman's space (BS) (PAS, 40x) 


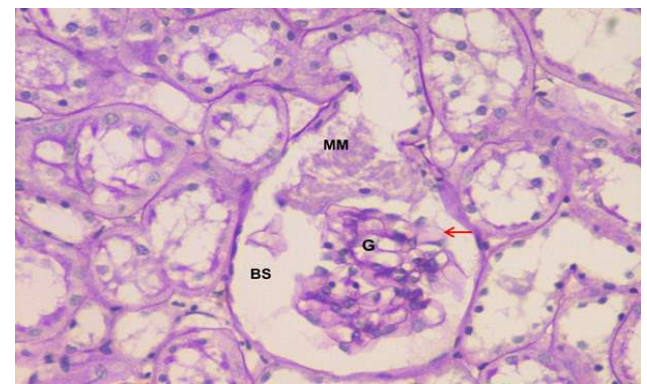

Fig.4 kidney photomicrograph of rat. Experimental (C Group) showing Cortex (CX). Glomerulus (G) with decreased mesangial matrix, increased Bowman's space (BS) (PAS, 40x)

Group) with narrowing of space between Bowman's capsule and glomerular capillary loops. Mesangial matrix was less increased in experimental group $\mathrm{C}$ which was treated with Ginger aqueous extract. Results coincided with the study conducted by Thing-Fong Tzeng et $\mathrm{al}^{27}$.

Ginger is a herb used due to its antioxidant properties ${ }^{14}$. It reduces the elevated blood glucose levels resulting in decreased formation of advanced glycosylation end-products (AGE). It reduces the blood glucose levels due to both pancreatic and extra pancreatic mechanisms. Pancreatic mechanisms include increased release of insulin from pancreatic beta cells or release of bound insulin ${ }^{17}$. Extra pancreatic mechanisms include increasing glucose utilization in liver or other tissues or by reducing intestinal glucose absorption $^{28}$. Ginger causes inhibition of oxidative damage and platelet aggregation ${ }^{29,30}$. It improves dementia, ulcerative colitis and cardiovascular diseases ${ }^{14,31}$. The effectiveness of ginger regarding prevention or suppression of cancer had been revealed in many types of cancer which include liver cancer, lymphoma, colorectal cancer, breast cancer, bladder cancer and skin cancer. The proposed mechanism of action includes induction of apoptosis, antioxidant activity, arrest in cell cycle, suppression of activator protein 1and decrease in proliferation ${ }^{31}$.

\section{CONCLUSION}

Results of this study indicated that treatment with Ginger aqueous extract reduced the progression of diabetic nephropathy induced by Alloxan in albino rats. Aqueous extract of Ginger showed amazing results histopathologically. The overall reno-protective effect of Ginger is probably due to a counteraction of free radicals by its antioxidant components and improvement of hyperglycemic state by pancreatic and extrapancreatic mechanisms. Further studies regarding higher dosages or longer periods of treatment are needed to see the protective effect of ginger on kidneys against diabetic nephropathy in human beings.

\section{ACKNOWLEDGEMENTS}

Authors would like to convey their sincere thanks to Prof.
Dr. Muhammad sohail, Dr. Sameera Haque, Dr. Ijaz Ahmed and Dr. Khalid Saeed and Dr. Mufassar Nishat for helping a lot in this research work.

\section{REFERENCES:}

1. Teoh SL, AbdLatiff A, Das S. Histological changes in the Kidneys of experimental diabetic rats fed with Momordica charantia (bitter gourd) Extract. Rom J Morphol Embryol. 2010; 51(1): 91-5.

2. Amritanshu K, Kumar A, Anand K, Garg N, Banerjee DP. Clinical profile and factors associated with microalbuminuria in type 1 diabetes mellitus in children and adolescents. Int. J.Res.Med.Sci. 2015; 3(5): 1247-51

3. Fowler MJ. Microvascular and Macrovascular Complications of Diabetes.Clin.Diabetes.2008; 26(2): 77-82.

4. Burkitt HG, Young B, Health JW. In:Wheaters functional histology.4th ed. London:Churchill Livingstone; 2000: 2826.

5. Ben Hamed SRS, Paukovic P, Metelko Z, Microalbuminuria and diabetes mellitus. Diabetologia Croatica 2002; 31(4): 209-20.

6. Soares AA, Prates AB, Weinert LS, Vernese FV, De Azevedo MJ, Silveiro SP. Referance values for glomerular filtration rate in healthy Brazilian adults. Biomed Cent.Nephrol. 2013; 14: 54 .

7. Alsaad Ko, Herzenberg AM. Distinguishing diabetic nephropathy from other causes of glomerulosclerosis: an update. J.Clin.Pathol.2007; 60: 18-26.

8. Vestra MD, Saller A, Bortoloso E, Mauer M, Fioretto P. Structural Involvement in Type 1 and Type 2 Diabeic Nephropathy.Diabetes Metab.2000; 26; 8-14.

9. Afshari AT, Shirpoor A, Farshid A, Saadatian R, Rasmi Y, Saboory E, Ilkhnizadeh B, Allameh A. The effect of ginger on diabetic nephropathy, plasma antioxidant capacity and lipid peroxidation in rats. J. Food Chemistry. 2007; 101: 148153.

10. Rohilla A, Ali S. Alloxan Induced Diabetes: Mechanisms and Effects. Int.J.Res.Pharm.Biomed.Sci. 2012; 3(2): 819-22.

11. Chidrewar GU, Mane Vs, Ghaisas MM, Deshpande AD. Dolichos biflorus Linn attenuate progression of renal damage in alloxan induced diabetic rats.Oriental. Pharm. Exp. Med.2010; 10(2): 134-140.

12. Chougale AD, Panaskar SN, Gurao Pm, Arvindekar AU. Optimization of Alloxan dose is essential to induce stable diabetes for prolonged period. Asian J Biochem 2007; 2(6): 402-408.

13. Jafri SA, Abass S, Qasim M. Hypoglycemic effect of ginger (Zingiber officinale) in Alloxan induced diabetic rats. Pak Vet J 2011; 31(2): 160-62.

14. Butt MS, Sultan MT. Ginger and its health claims: Molecular aspects. Crit Rev Food Sci Nutr 2011; 51: 383-393.

15. J Shah, M Patel, K Patel, T Gandhi. Evaluation of Antidiabetic and Anti-oxidant Activity of Centratherum anthelmintica in STZ - induced Diabetic Rats. Internet.J. Pharmacol 2007; 6(1): 16.

16. El-Kott AF, El-sayad SM, Abdel-Aziz AM. The effects of ginger (zingiber officinale) on histology and immunohistochemistry of liver and kidney and certain haematological parameters in alloxan induced diabetic rats. Egypt. J.Exp. Biol. (zool).2010; 6(1): 61-70. 
17. Ramudu SK, Korivi M, Kesireddy N. Lee LC, Cheng IS, Kuo $\mathrm{CH}$, Kesireddy SR. Nephroprotective effects of a ginger extract on cytosolic and mitochondrial enzymes against streptozocin (STZ) induced diabetic complications in rats. Chin J Physiol 2011; 54(2): 79-86.

18. Al-kushi AG. Biochemical and Ultrastructure Changes in the Kidney of Streptozotocin-induced Diabetic Rat. Pak.J.nutr. 2013; 12(4): 313-321.

19. A Compendium of Drugs Used for Laboratory Animal Anesthesia, Analgesia, Tranquilization and Restraint. [Cited 2012 Aug 29]. Available from: URL: http://www.lebi.ucr.ac.cr/ files/Anestesial/IACUC_drugs.pdf

20. Euthanasia Guidelines. [Cited 2012 Aug 30]. Available from: URL:http:// www.ahc.umn.edu/rar/euthanasia.html

21. Gamble M. The Hematoxylins and Eosin. In Theory and Practice of Histological Techniques, 6th, Churchill Livingstone Elsevier, Philadelphia, PA, USA. 2008; 121-134.

22. Totty BA. Mucins. In: Bancroft JD, Gamble M, editors. Theory and practice of histologic techniques. 5th ed. London: Churchill Livingstone; 2002: 175.

23. Libman I, Arslanian S. Type 2 diabetes in childhood: the American perspective. HormRes. 2003; 59 Suppl 1:S69-76.

24. Nand N, Aggarwal HK, Sharma M. Renal Replacement Therapy in Diabetic Nephropathy: An Update. J.Indian.Acad. Clin. Med.2002; 3(1): 81-84.
25. Nawale RB, Mourya VK, Bhise SB. Non-enzymatic glycation of proteins: A cause for complications in diabetes. Indian. J. Biochem. Biophys .2006; 43; 337-344.

26. Cohen Tervaert TW. Mooyaart AL, Amann K et all. Pathologic Classification of Diabetic Nephropathy. J.Am.soc.Nephrol. 2010; 21: 556-563.

27. Tzeng TF, Liou SS, Cnang CJ, Liu IM. Zerumbone, a tropical ginger sesqiiterpene, ameliorates streptozotocin-induced diabetic nephropathy in rats by reducing the hyperglycemiainduced inflammatory response. Nutr.Metab.2013; 10: 64.

28. Kaejaiye OF, Iwalewa EO, Omobuwajo OR, Oyedapo OO. Hypogycemic effects of Nigerian Zingiber Officinale Rhizome on experimental diabetic rats. Nig J Nat Prod and Med 2002; 06: 33-35.

29. Kemper KJ. Ginger (Zingiber officinale). [online] 1999 Nov 3 [cited 2013 Nov 21]. Available from: URL: http://www.longwoodherbal.org/ginger/ginger.pdf

30. Thorne Research. Zingiber officinale (Ginger). [online] 2003 [cited 2013 Dec 8]. Available from: URL: http://www.thorne. com/ altmedrev/.fulltext/8/3/331.pdf

31. Bode Am, Dong Z. The Amazing and Mighty Ginger. In: Benzie IFF, Washtel-Galor S. Herbal Medicine: Biomolecular and Clinical Aspects. 2nd ed. Boca Ratoon (FL): CRC Press; 2011. Chapter 7. 